\title{
A rare large mutation involving two exons of the SP-B gene in an infant with severe respiratory distress
}

\author{
Şahin Takc1 ${ }^{1}$, Deniz Anuk-İnce ${ }^{2}$, Malek Louha ${ }^{3}$, Remy Couderc ${ }^{3}$, Nursen Çakar ${ }^{1}$, Reşit \\ Doğan Köseoğlu ${ }^{4}$, Ömer Ateş 5 \\ ${ }^{1}$ Department of Pediatrics, Gaziosmanpasa University Faculty of Medicine, Tokat; ${ }^{2}$ Department of Pediatrics, Baskent \\ University Faculty of Medicine, Ankara; ${ }^{3}$ Department of Biochemistry, Armand Trousseau Hospital, Paris, France; \\ ${ }^{4}$ Department of Pathology, ${ }^{5}$ Deparment of Molecular Biology and Genetics, Gaziosmanpasa University Faculty of Medicine, \\ Tokat, Turkey.E-mail: stakci@gmail.com
}

Received: 16th March 2017, Accepted: 11th April 2017

SUMMARY: Takcı Ş, Anuk-İnce D, Louha M, Couderc R, Çakar N, Köseoğlu $\mathrm{RD}$, Ateş Ö. A rare large mutation involving two exons of the SP-B gene in an infant with severe respiratory distress. Turk J Pediatr 2017; 59: 483-486.

Hereditary surfactant protein-B (SP-B) deficiency is a rare autosomal recessive disease of newborn infants causing severe respiratory failure and death within the first year of life. The most common cause of SP-B deficiency is a frameshift mutation in exon 4 (121ins2) in the gene encoding SP-B. We report a term infant with unremitting respiratory distress who was unresponsive to all treatment modalities. The parents were consanguineous and a term sibling of the infant had died due to respiratory failure without a certain diagnosis. In the first step of the diagnostic work-up, common genetic mutations for SP-B, surfactant protein C and ATP-binding cassette s3 were absent, however sequencing of SP-B gene revealed a large homozygous genomic deletion covering exon 8 and 9.

In this case report, we aimed to emphasize further genetic evaluation in all cases suggestive of surfactant dysfunction, even if common mutations are absent.

Key words: surfactant protein $B$, severe, respiratory distress syndrome, term.

Respiratory problems are common in the early neonatal period and take an extensive place in the neonatal practice. A majority of cases are premature infants with respiratory distress syndrome or chronic lung disease. However, there are a significant number of full-term infants admitted to the neonatal intensive care units for respiratory distress. Beside well known diseases, such as transient tachypnea of the newborn, meconium aspiration syndrome, pulmonary hypertension and pneumonia, some diseases are very rare and constitute a diagnostic challenge in full-term infants. These mainly include miscellaneous infections, structural abnormalities of the lung and genetic disorders of surfactant dysfunction. ${ }^{1,2}$

Here, we report the case of a full-term infant with severe respiratory distress with a very rare type of surfactant protein-B (SP-B) gene mutation.

\section{Case Report}

A 38-week-gestation male infant with a birth weight of 3,130 g was delivered by cesarean section to a 24 year old gravida 2 , para 2 mother after an uneventful pregnancy. His parents were first cousins. The mother had no known prenatal disease history such as infection or diabetes. The sibling of the infant, who was born at full-term had died at 15 days of age with pulmonary hypertension and a suspicion of congenital pneumonia. The Apgar scores were 8 and 8 at 1 and $5 \mathrm{~min}$, respectively. The infant developed respiratory distress 1 hour after birth. The physical examination revealed grunting, cyanosis and tachypnea with subcostal and intercostal retractions. Initially, he was transferred to the neonatal intensive care unit and received continuous positive airway pressure (CPAP) support with a $50 \%$ supplemental oxygen. A treatment regimen of intravenous ampicillin and 
gentamicin therapy, was also started. Despite respiratory support and antibiotic therapy, the infant's clinical condition deteriorated over a few hours. He was intubated and ventilated with conventional mechanical ventilation. Chest radiography showed a diffuse granular pattern compatible with surfactant deficiency (Fig. 1). Echocardiography was normal. A $200 \mathrm{mg} / \mathrm{kg}$ dose of exogenous surfactant treatment was given on the first day of life. The infant was extubated and treated with CPAP soon after surfactant administration. On the third day of life, the infant's health degraded and the baby was put on conventional mechanical ventilation again. Dopamine and dobutamine were administered to maintain normal blood pressure. Second and third doses of exogenous surfactant were given on the third and sixth days of life, which resulted in a mild and transient improvement on oxygenation. Repeated evaluations for infections were negative, with normal white blood count, immature/total neutrophil ratio, C-reactive protein and negative blood cultures. During the following days, respiratory failure progressed. $\mathrm{FiO}_{2}$ was increased to 1.0 and the ventilation treatment was changed to high frequency oscillatory ventilation. Low dose of intravenous dexamethasone therapy was added to the treatment on day 30 . However, all these approaches failed to improve severe hypoxemia and respiratory acidosis. The infant died of respiratory failure at 43 days of life. Informed

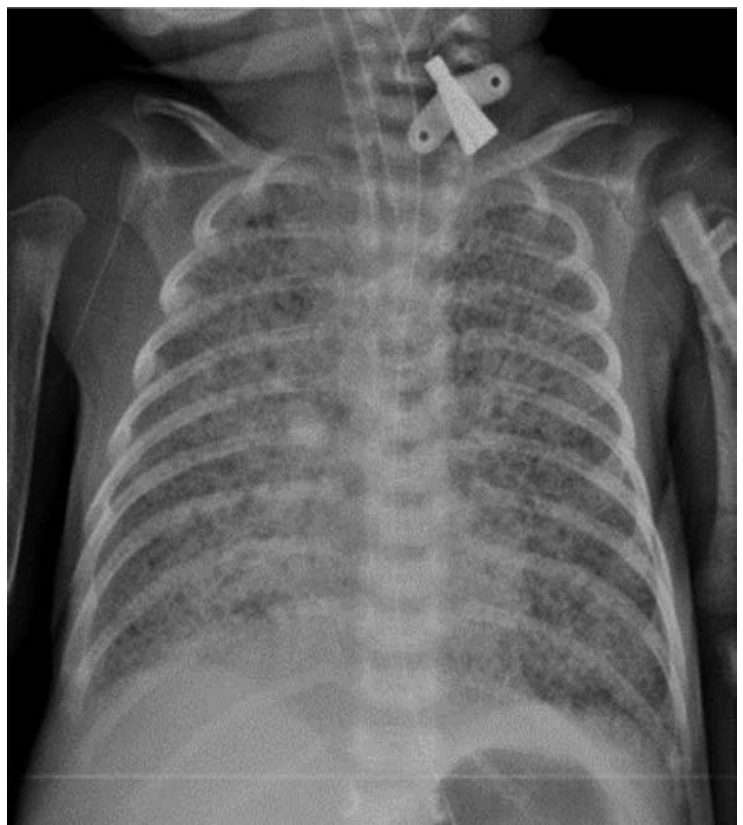

Fig. 1. Chest radiography showed a diffuse granular pattern compatible with severe RDS

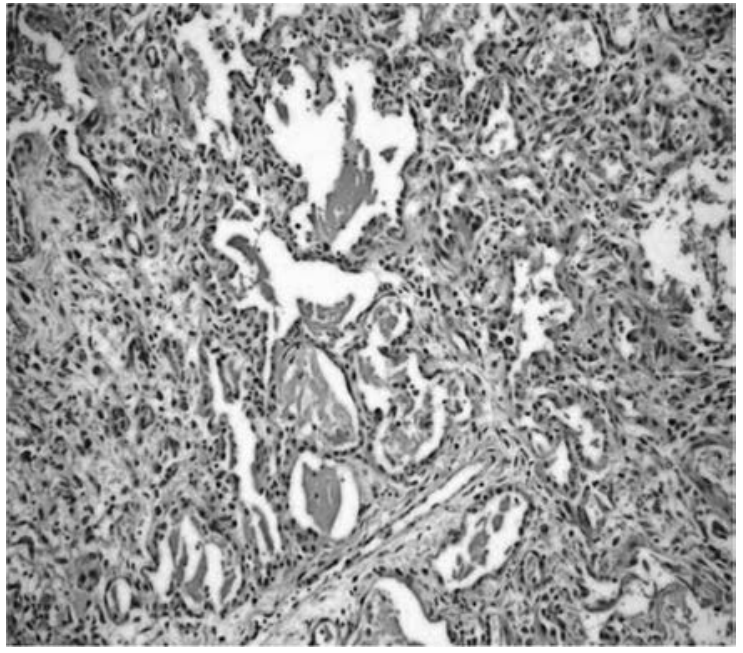

Fig. 2. Histopathologic examination of the lung tissue. Intraalveolar accumulation of eosinophilic hyaline membranes are shown (haematoxylin-eosin stain, original magnification $\times 20$ )

consent for genetic testing for hereditary surfactant deficiencies and post-mortem open lung biopsy were obtained from the parents. Histopathologic examination of the lung tissue showed diffuse collapse of the airspaces and eosinophilic hyaline membranes lining the remaining alveolar spaces (Fig. 2).

The initial genetic evaluation revealed the absence of common mutations of SFTPB (121ins2), surfactant protein C [SFTPC (173T)] and ATP-binding cassette protein subfamily A $[(A B C A 3)(E 292 \mathrm{~V})]$. Also no mutation has been identified in the entire coding sequence and exon-intron junctions of SFTPC and $A B C A 3$ genes. subsequent DNA sequencing of $S F T P B$ identified a very rare large homozygous genomic deletion c.708+194_1039-28del or chr2. hg38: g.85665095_85662137del spanning 2959 base pairs and covering exon 8 and 9 of the SFTPB gene (NM-000542.3) Both parents were heterozygous for that gene mutation, confirming an autosomal recessive pattern of inheritance. A schematic representation of a breakpoint spanning PCR validating the deletion in the index patient and his parents is shown in Figure 3.

Informed consent was obtained from the parents of the infant for presenting this case.

\section{Discussion}

The pulmonary surfactant is a complex mixture of phospholipids and proteins needed to reduce alveolar surface tension and to prevent end-expiratory collapse. The phospholipid 
component represents approximately $90 \%$ of the surfactant that performs the surface-tensionlowering function. The protein component forms the remaining $10 \%$ by weight of the surfactant. Surfactant proteins are necessary for surfactant biosynthesis and metabolism and to provide immune functions. There are four surfactant proteins named SP-A, SP-B, SP-C and SP-D. SP-A and SP-D participate in host defense in the lung, whereas SP-B and SP-C play an important role in the metabolism and dynamics of the lipids of pulmonary surfactant ${ }^{3}$. As the structure and function of the surfactant proteins are different, the clinical outcome of the surfactant protein deficiency could be variable. Particularly SP-B is the only surfactant protein strictly required for breathing, as indicated by previous experimental studies and case reports showing that the inability to produce SP-B results in lethal respiratory failure. ${ }^{4,5}$

Hereditary SP-B deficiency is a rare autosomal recessive disease, first recognized in full-term infants in 1993. 6 Affected infants develop severe progressive respiratory failure in spite of all aggressive treatment modalities. Clinical estimates suggest that SP-B deficiency has an incidence of 1 per million live births, whereas the frequency of the 121 ins 2 mutation is approximately 1 per 1000 individuals $^{3}$. SP-B is encoded by SFTPB gene located on the short arm of chromosome 2 and consists of 12 exons (exon 1 and 12 non-coding) (NM_000542.3, variant 1). More than 40 distinct mutations have been identified in the SFTPB gene to date. The most common mutation, which amounts to two thirds of the mutant alleles, is a net

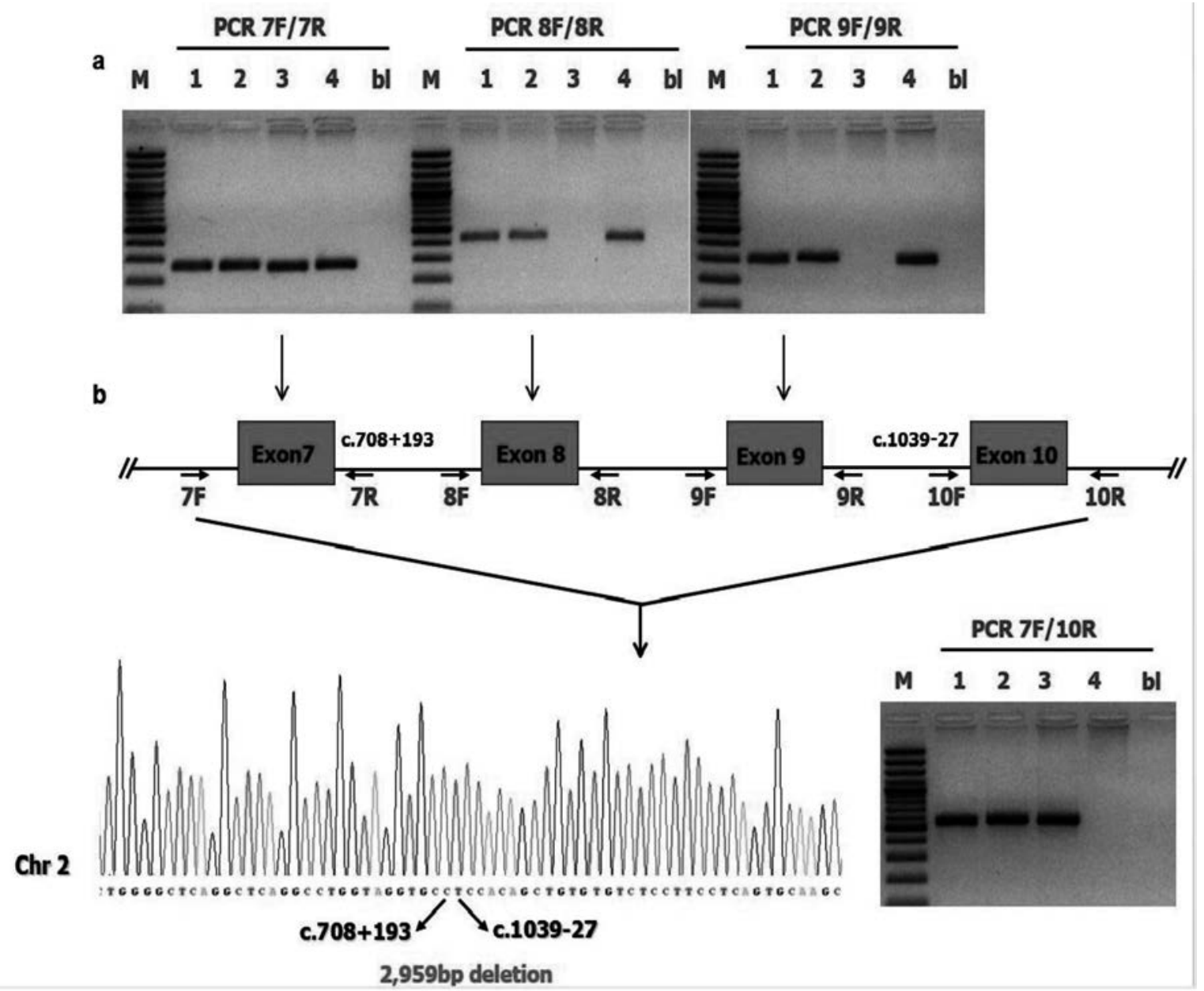

Fig. 3. (a) SFTPB genomic sequence of the newborn patient around the breakpoint and schematic representation of part of the SFTPB gene (RefSeq: NM_000542.3) exons are indicated as blocks, introns as lines and PCR primers as arrows. (b) PCR amplification of genomic DNA from the newborn patient (lane 3), parents (lanes 1 and 2) and an unaffected control (lane 4). 100-bp molecular weight marker (lane M), only buffer without DNA (lane bl). In the newborn patient exons 8 and 9 of SFTPB were not amplified in the corresponding PCR reaction, while a PCR product was obtained by using PCR primers 7 forward (7F) and 10 reverse (10R). The same amplicon (PCR 7F/10R) was amplified in the parents and not in the unaffected control suggesting the presence of a homozygous large rearrangement in the patient. 
2-bp insertion at codon 121 in exon 4 of the SFTPB (121ins2).

Although the incidence is very rare, SP-B deficiency is suggested to be underdiagnosed. These infants commonly present with unremitting hypoxemic respiratory failure after an uncomplicated pregnancy and delivery. Regarding the autosomal recessive inherited pattern, a family history of affected siblings may present in some cases. ${ }^{7}$ In the present case, the full-term infant was born after an uneventful pregnancy and his respiration deteriorated within hours after delivery. The parents were consanguineous and had already lost a child due to respiratory failure. Based on the clinical manifestations, we suspected the possibility of a surfactant mutation that could affect the SFTPB and ABCA3 genes. The most frequent gene mutations in these two genes, 121 ins 2 for SFTPB and E292V for ABCA3, were not found during the first step of our genetic testing. Additional sequencing analysis showed a large homozygous genomic deletion of the SFTPB gene, described as c. $708+194$ 103928del (NM_000542.3). This deletion produces the loss of in-frame exons 8-9, generating a protein lacking amino acids 225-334 (p.Gly225 Lys334del) (NP_000533.3). To date, a variety of SFTPB mutations were described including nonsense, missense, frameshift, and splice-site mutations, as well as minor insertions and deletions through the gene. Large deletions spanning exons 7 and 8, corresponding to exons 8 and 9 (NM_000542.3) have also been reported previously in two separate cases. ${ }^{5,8}$ To the best of our knowledge, our case is the third case encompassing multiple exons of the SFTPB gene. The descent of our patient is Turkish and the previous infants are Azerbaijani and Kurdish suggesting that this type of SFTPB mutation may have an importance in these regions.

The differential diagnoses include hereditary ABCA3 deficiency and congenital alveolar capillary dysplasia with misalignment of pulmonary veins (ACDMPV).${ }^{9}$ Analysis of post mortem lung tissue ruled out ACDMPV, since none of the prominent pathologic features, such as decrease number of pulmonary capillaries located away from the alveolar epithelium and hypertrophy of pulmonary arteries, could be observed.

As a limitation of the case, an immunochemical analysis demonstrating the absence of SP-B could not be performed due to technical restrictions.

No specific treatment for SP-B deficiency is available to date. Exogenous surfactant is ineffective and provides only transient improvement in gas exchange. Currently, the only described successful treatment of SP-B deficiency is lung transplantation. After transplantation, the 5-year survival rate is approximately $50 \% .^{3}$ Identifying the diseasecausing mutation in the index case however, allows to provide genetic counseling to the affected families. Parents described in this case received preimplantation genetic diagnosis and had a healthy baby.

In conclusion, full-term infants with profound respiratory failure and who appear refractory to all treatment modalities are strong candidates for the evaluation of hereditary SP-B deficiency. We emphasize further genetic evaluation in all cases suggestive of surfactant dysfunction, even if common mutations are absent.

\section{REFERENCES}

1. Parker TA, Kinsella PJ. Respiratory failure in the term newborn. In: Gleason CA, Devaskar SU (eds). Avery's Diseases of the Newborn ( $9^{\text {th }}$ ed). Philadelphia: Elsevier Saunders, 2012: 647-657.

2. Abdel-Latif ME, Oei J, Ward M, Wills EJ, Tobias V, Lui K. Galvanised by a respiratory distress diagnosis. Arch Dis Child Educ Pract Ed 2008; 93: 112-119.

3. Hamvas A. Inherited surfactant protein-B deficiency and surfactant protein- $\mathrm{C}$ associated disease: Clinical features and evaluation. Semin Perinatol 2006; 30: 316-326.

4. Melton KR, Nesslein LL, Ikegami M, et al. SP-B deficiency causes respiratory failure in adult mice. Am J Physiol Lung Cell Mol Physiol 2003; 285: 543-549.

5. Schuerman FA, Griese M, Gille JP, Brasch F, Noorduyn LA, van Kaam AH. Surfactant protein-B deficiency caused by a novel mutation involving multiple exons of the SP-B gene. Eur J Med Res 2008; 13: 281-286.

6. Nogee LM, Garnier G, Dietz HC et al. A mutation in the surfactant protein-B gene responsible for fatal neonatal respiratory disease in multiple kindreds. J Clin Invest 1994; 93: 1860-1863.

7. Wilder MA. Surfactant protein-B deficiency in infants with respiratory failure. J Perinat Neonatal Nurs 2004; 18: 61-67.

8. Wegner DJ, Hertzberg T, Heins HB, et al. A major deletion in the surfactant protein-B gene causing lethal respiratory distress. Acta Paediatr 2007; 96: 516-520.

9. Bishop NB, Stankiewicz P, Steinhorn RH. Alveolar capillary dysplasia. Am J Respir Crit Care Med 2011; 184: 172-179. 